\title{
Effect of Bentonite on the Yield and Composition of Products From Thermolysis of Polystyrene Waste
}

\author{
Lety Trisnaliani $^{1{ }^{1 *}}$ Aida Syarif ${ }^{1}$ Sahrul Effendy ${ }^{1}$ Tahdid $^{1}$ Rima Daniar $^{1}$
}

\author{
${ }^{1}$ Politeknik Negeri Sriwijaya \\ ${ }^{*}$ Corresponding author. Email: Lety.trisnaliani@polsri.ac.id
}

\begin{abstract}
Economic growth and population explosion are chronic problems in big cities which trigger an increase in energy consumption in society. The flow of plastic used has been a dilemma for a long time, so there are thoughts on how to turn plastic waste into something that can be useful. One of the polystyrene plastic wastes can be processed into liquid fuel by cracking. In this research, the process of cracking polystyrene plastic had been conducted by a catalytic cracking process using a bentonite catalyst. This research aims to be determined the effect of the percentage of the catalyst on the percentage of product yield and the characteristics resulting from the catalytic cracking of polystyrene plastic waste using a bentonite catalyst. The catalytic cracking process will be carried out in a thermal catalytic reactor where the process takes place at a temperature of $250^{\circ} \mathrm{C}$ with a cracking time of 20,40 and 60 minutes and the weight of catalyst 4, 6 and $8 \%$ as polystyrene waste is 250 gr. The analysis carried out on the final product is a GCMS analysis showed the characteristic nearly to a standard gasoline.
\end{abstract}

Keywords: Bentonite, Yield, Thermolysis, Polystyrene, Plastic Waste

\section{INTRODUCTION}

The extraordinary increase in worldwide consumption of plastics for a wide variety of products is causing serious waste disposal and environmental problems. One of the most dominant plastic waste is plastic made from polystyrene, which is a plastic material that is safe for use by the community because this based plastic has properties that tend to be tougher and resistant to high temperatures and is not translucent 0 . Thus, it is widely used as a common plastic material. Polystyrene plastic is often found in the form of plastic bags, food containers, tires and others. This reminds us of the importance of plastic recycling and processing technology to deal with this problematic waste in an environmentally friendly way [1]. Nox, Sox, Cox etc creates potentially harmful gaseous by products that could contaminant groundwater and air [3]. To convert plastic waste to liquid fuel is an alternative to manage it.

Pyrolysis is a promising technology used to convert plastic waste into liquid oil and other valuable byproducts such as charcoal and gas under controlled conditions and is considered a relatively more environmentally friendly technology than uncontrolled combustion [4]. The product pyrolysis yield depends on a number of process parameters such as temperature, heating rate, moisture content, retention time, plastic type and particle size. Yields of up to $80 \%$ of liquid oil by weight can be achieved from plastic waste [5]. The resulting liquid oil has similar characteristics to conventional diesel including, density $\left(0.8 \mathrm{~kg} / \mathrm{m}^{3}\right)$, viscosity (up to $2.96 \mathrm{~mm}^{2} / \mathrm{s}$ ), flash point $\left(30.5^{\circ} \mathrm{C}\right)$ and energy content $(41.58 \mathrm{MJ} / \mathrm{kg})$, and can be used as an energy source. Tar produced from pyrolysis can be activated under standard conditions for use in wastewater treatment, heavy metal removal, and smoke and odor removal. The gases produced from pyrolysis are $\mathrm{H}_{2}, \mathrm{CO}$ and $\mathrm{CO}_{2}$ and can be used as energy carriers. High temperatures and retention times are the main limitations of plastic waste pyrolysis, which need to be optimized to make the process more economical and environmentally friendly [6].

This research will optimize the conversion process of polystyrene plastic waste using a thermal cracking / pyrolysis reactor with a bentonite catalyst to produce liquid fuel that has almost the same characteristics as conventional liquid fuel (gasoline).

Based on the above background, research will be carried out on the conversion of polystyrene plastic into liquid fuel using a bentonite catalyst in a thermal 
cracking reactor. In this study, the fixed variables are the amount of raw material and temperature, while the variable is the percentage of catalyst. The problem that will be discussed by the researcher is to know the characteristics of the thermolysis product of polystyrene plastic waste in the form of density, spgr and API Gravity in accordance with the standards and quality of the Directorate General of Oil and Gas No.0117.K / 10 / DJM.T / 2018 [7] which is influenced by temperature and performs compound analysis liquid fuel chemistry using GC-MS based on the highest\% yield obtained.

\section{LITERATURE REFENCES}

Plastics are a type of macromolecule formed by a polymerization process. Polymerization is the process of combining several simple molecules (monomers) through a chemical process into large molecules (macromolecules or polymers). Plastics are polymer compounds whose main constituent elements are carbon and hydrogen. To make plastics, one of the most commonly used materials is naphtha, which is a material produced from refining petroleum or natural gas. As an illustration, to make $1 \mathrm{~kg}$ of plastic requires $1.75 \mathrm{~kg}$ of petroleum, to meet the needs for raw materials and energy needs for the process [8].

Polystyrene is a polymer plastic that is easily formed when heated, the molecular formula is $\left(\mathrm{CHC}_{6} \mathrm{H}_{5}-\mathrm{CH}_{2}-\right)$ $\mathrm{n}$ [9]. Very stiff at room temperature. Polystyrene can be found in plastic utensils, CD cases, plastic cups, food containers, trays and smoke detector housings [10].

Pyrolysis, also called thermolysis (Greek: pur = fire, thermos = warm; luo = loosening), is a chemical and thermal decomposition process, generally leading to smaller molecules. Thermolysis is a more appropriate term than pyrolysis because fire indicates the presence of oxygen. In most pyrolysis processes, air is removed for reasons of safety, product quality and yield. Pyrolysis can be carried out at various temperatures, reaction times, pressures, and in the presence or absence of gases or liquids, and reactive catalysts. The thermal pyrolysis process takes place at temperatures between $500-800^{\circ} \mathrm{C}$ and is generally carried out at atmospheric pressure [11].

Bentonite is a commercial term for clay containing montmorillonite and a dioctohedral group. Bentonite is the result of sedimentation from volcanic activity of very fine falls which then undergoes the process of being worked on by water and re-deposited in other areas, possibly in the deep sea environment.

The physical properties of bentonite include a waxy finish, generally soft and plastic. Pale in color with the appearance of white, light green, gray to pink in a fresh state and becomes creamy when weathered which then turns yellow, red brown to black. When you touch it feels slippery like soap. When put into water, it will absorb water, a little or a lot, if it is exposed to rain water, bentonite can turn into slurry and when it dries it will cause noticeable cracks. Other physical properties are density 2,2-2,8 g / L; refractive index from 1.547 to 1.557; and a melting point of $1330-1430{ }^{\circ} \mathrm{C}$.

\section{EXPERIMENT}

The raw materials used in this research are polystyrene plastic in the form of food and cosmetic packaging waste Bentonite catalyst is purchased directly from the Bratachem company. The experimental procedure for converting plastic waste into liquid fuel using a bentonite catalyst and a thermal catalytic reactor. There are two kinds of polystyrene plastic waste that is used in this research. These are food container and foam packaging. Food particle are cleaned with liquid soap and water inside laboratory by manually, then drying naturally by using sunlight. After that food container and foam packaging are shredded into small pieces by using wire brush. Selected particle size range to set is between $4 \mathrm{~mm}$ and $6 \mathrm{~mm}$. Prepared raw materials are weighted by using digital balance. Catalyst obtained from Bratachem company couldn't directly use. It should be treated to activate the catalyst. In this research to activate the catalyst, it is used thermal method. Catalyst is placed in Porcelain dish, then put into the oven for 3 hours at temperature $300^{\circ} \mathrm{C}$.

\subsection{Catalytic Cracking of Polystyrene}

Post-consumer, municipal solid waste mixed polystyrene obtains from several communities in Palembang city. Polystyrene plastic waste cleaned by using soap and water then drying naturally under sunlight. The size reduction of polystyrene using scissor to cut the particle size into $4-6 \mathrm{~mm}$. Bentonite catalyst mixed with feed, its varied 4,6 and $8 \%$ of the total load. A semi-batch unstirred stainless-steel reactor is operated at $250^{\circ} \mathrm{C}$ and using time 20,40 and 60 minutes to liquefy them. The fuel oil will be collected and kept for further analysis. To analyze the composition contained in the liquid fuel resulting from catalytic pyrolysis, a GC-MS test was carried out at the Laboratory with the required sample size of $10 \mathrm{ml}$.

\section{RESULT AND DISCUSSION}

In the catalytic cracking process, the reaction is performed at the temperature $250^{\circ} \mathrm{C}$, the catalyst was used is bentonite as much as $4 \%, 6 \%$, and $8 \%$. The cracking time was varied, which are 20, 40 and 60 minutes. Liquid, solid and gases are the main products of process. 
The detailed product distribution is as listed in Table

Catalytic cracking breaks down the long chain of hydrocarbons (polymers) present in waste plastic into short chain hydrocarbons that resemble fuel. Catalytic catalyst $6 \%$, the highest conversion is $83.36 \%$, for the catalyst $8 \%$, the highest conversion is $85.92 \%$. And so is the liquid yield percentage, without catalyst the highest liquid yield percentage is $9.76 \%$. For catalyst 4 $\%$, the highest liquid yield percentage is $13.28 \%$. For

Table 1. Product Distribution of Catalytic Cracking Process of Polystyrene

\begin{tabular}{|c|c|c|c|c|c}
\hline Cracking Time (minutes) & Catalyst $(\%)$ & Operating Temp $\left({ }^{\circ} \mathrm{C}\right)$ & Liquid $(\mathrm{g})$ & Solid $(\mathrm{g})$ & Gas $(\mathrm{g})$ \\
\hline 20 & 0 & 250 & 20.1 & 68.3 & 161.6 \\
\hline 40 & 0 & 250 & 22.6 & 65.7 & 161.7 \\
\hline 60 & 0 & 250 & 24.4 & 63.6 & 162.0 \\
\hline 20 & 4 & 250 & 24.6 & 62.2 & 163.2 \\
\hline 40 & 4 & 250 & 28.3 & 58.1 & 163.6 \\
\hline 60 & 4 & 250 & 33.2 & 53.1 & 163.7 \\
\hline 20 & 6 & 250 & 35.8 & 49.5 & 164.7 \\
\hline 40 & 6 & 250 & 43.3 & 47.4 & 164.9 \\
\hline 60 & 6 & 250 & 41.6 & 165.1 \\
\hline
\end{tabular}

cracking process yielded three different products. The yield percentage of product obtained is showed in Table 2.

According to table 2, the increase of cracking time increased conversion and yield percentage. Without catalyst, the highest conversion is $74.56 \%$. For the catalyst $4 \%$, the highest conversion is $78.76 \%$. For the catalyst $6 \%$, the highest liquid yield percentage is $17.32 \%$. For catalyst $8 \%$, the highest liquid yield percentage is $19.36 \%$. The solid yield was almost constant in all the experiments. The gas and liquid were strongly influenced by cracking time. Percentage of liquid and gas yield were increased at longer cracking time. As cracking time increased, liquid yield was also increased and so was gas yield.

Table 2. The conversion and yield percentage of products of polystyrene catalytic cracking process

\begin{tabular}{|c|c|c|c|c|c|c|}
\hline \multicolumn{3}{|c|}{ Research Variable } & \multirow[t]{2}{*}{$\%$ Conversion } & \multicolumn{3}{|c|}{$\%$ Yield } \\
\hline $\begin{array}{l}\text { Cracking Time } \\
\text { (minutes) }\end{array}$ & $\begin{array}{c}\text { Reaction Temp. } \\
\text { (T) }{ }^{\circ} \mathrm{C}\end{array}$ & Catalyst (\%) & & Liquid (g) & Solid (g) & Gas (g) \\
\hline 20 & 250 & 0 & 72.68 & 8.04 & 27.32 & 64.64 \\
\hline 40 & 250 & 0 & 73.72 & 9.04 & 26.28 & 64.68 \\
\hline 60 & 250 & 0 & 74.56 & 9.76 & 25.44 & 64.80 \\
\hline 20 & 250 & 4 & 75.12 & 9.84 & 24.88 & 65.28 \\
\hline 40 & 250 & 4 & 76.76 & 11.32 & 23.24 & 65.44 \\
\hline 60 & 250 & 4 & 78.76 & 13.28 & 21.24 & 65.48 \\
\hline 20 & 250 & 6 & 80.20 & 14.32 & 19.80 & 65.88 \\
\hline 40 & 250 & 6 & 81.04 & 15.08 & 18.96 & 65.96 \\
\hline 60 & 250 & 6 & 83.36 & 17.32 & 16.64 & 66.04 \\
\hline 20 & 250 & 8 & 83.80 & 17.40 & 16.20 & 66.40 \\
\hline 40 & 250 & 8 & 84.40 & 17.88 & 15.60 & 66.52 \\
\hline 60 & 250 & 8 & 85.92 & 19.36 & 14.08 & 66.56 \\
\hline
\end{tabular}


Liquid yield percentage of product at different cracking time is shown in figure 1 . The longer cracking time and more catalyst added, percentage of liquid yield was increased. From that figure, it's known that the highest percentage of liquid yield is sample with $8 \%$ catalyst and cracking time 60 minutes that is $19.36 \%$. Hazrat et al., 2015 explained that the increase of catalyst content increases the amount of desired fuel of liquid products, there is an optimal range. The conversion efficiency even decreases after the optimal range of catalyst to waste plastic ratio based on the type of catalyst, plastic and reaction temperature.

Conversion percentage of product at different cracking time is shown in figure 2 . The longer cracking time and more catalyst added, percentage of conversion was increased. From that figure, it's known that the

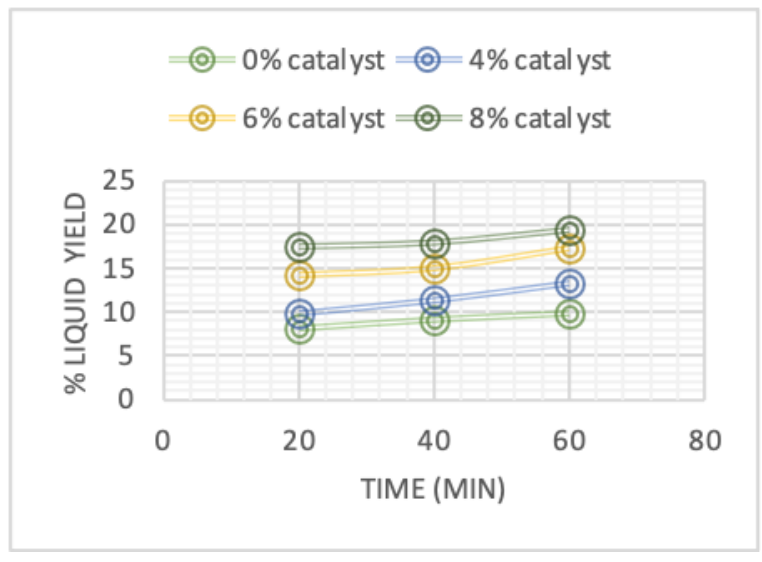

Figure 1. Effect of cracking time on liquid yield

highest percentage of liquid yield is sample with $8 \%$ catalyst and cracking time 60 minutes that is $85.92 \%$. Liquid yield percentage of product at different catalyst amount is shown in figure 3 . As catalyst amount increased, conversion percentage was also increased. From the figure, it's known that the highest percentage

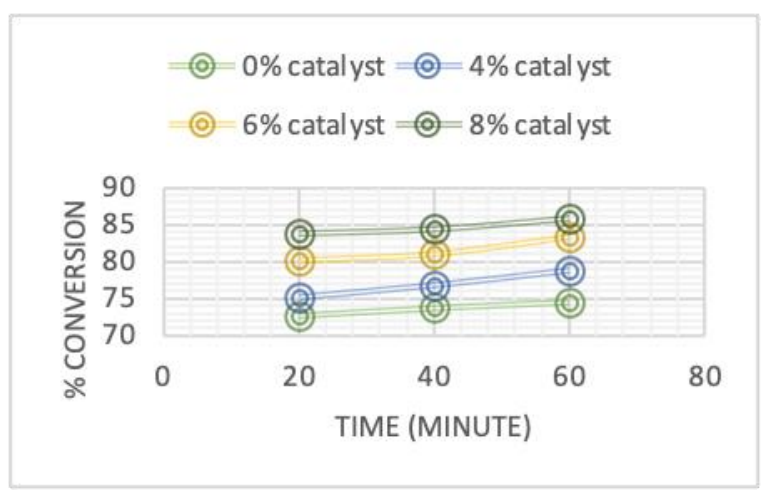

Figure 2. Effect of cracking time on conversion percentage is sample with 60 minute cracking time and $8 \%$ catalyst that is $19.36 \%$. The increasing of catalyst amount, increased \% liquid yield. Catalyst helps reducing the activation energy of the feedstock so that the required temperature in the thermal cracking process is reduced [12]. The ratio between catalyst and the polymer waste also controls the liquid fuel conversion efficiency of the process.

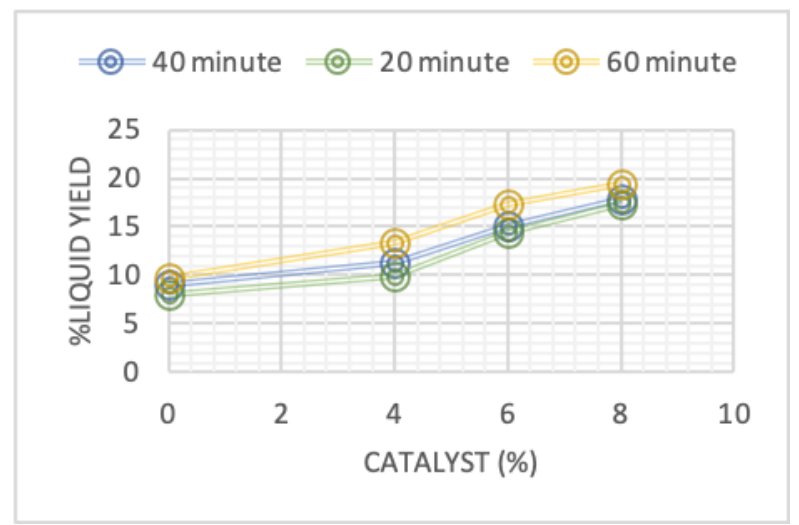

Figure 3. Effect of catalyst amount on liquid

Conversion percentage of product at different catalyst amount is shown in figure 4. As catalyst

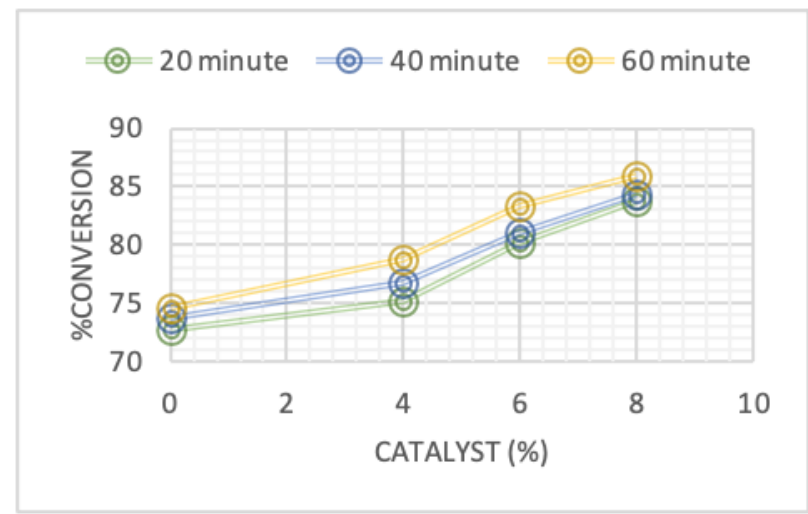

Figure 4. Effect of catalyst amount on conversion percentage

amount increased, conversion percentage was also increased. From the figure,its known that the highest percentage is sample with 60 minute cracking time and $8 \%$ catalyst, that is $85.92 \%$. The increasing of catalyst amount, increased $\%$ conversion.

The obtained liquid from thermo catalytic cracking process was characterized as it was without any futher processing. The fuel properties like density $(\mathrm{g} / \mathrm{mL})$, spgr, and API gravity was measured. As given the table 3. 
Table 3. Physical properties of liquid fuel from polystyrene plastic waste

\begin{tabular}{|c|c|c|c|c|c|}
\hline \multicolumn{3}{|c|}{ Research Variable } & \multicolumn{3}{|c|}{ Analyzed Parameters } \\
\hline $\begin{array}{c}\text { Cracking Time } \\
\text { (minutes) }\end{array}$ & $\begin{array}{l}\text { Reaction Temp. } \\
\text { (T) }{ }^{\circ} \mathrm{C}\end{array}$ & $\begin{array}{l}\text { Catalyst } \\
(\%)\end{array}$ & Density (g/ML) & Spgr & API Gravity \\
\hline \multicolumn{3}{|c|}{ Gasoline Standard } & $0.735-0.755$ & 0.7528 & 50.46 \\
\hline 20 & 250 & 0 & 0.747 & 0.762 & 54.1 \\
\hline 40 & 250 & 0 & 0.753 & 0.768 & 52.6 \\
\hline 60 & 250 & 0 & 0.761 & 0.776 & 50.7 \\
\hline 20 & 250 & 4 & 0.719 & 0.734 & 61.2 \\
\hline 40 & 250 & 4 & 0.720 & 0.735 & 61.0 \\
\hline 60 & 250 & 4 & 0.756 & 0.772 & 51.9 \\
\hline 20 & 250 & 6 & 0.760 & 0.776 & 50.9 \\
\hline 40 & 250 & 6 & 0.762 & 0.777 & 50.6 \\
\hline 60 & 250 & 6 & 0.753 & 0.768 & 52.6 \\
\hline 20 & 250 & 8 & 0.756 & 0.772 & 51.9 \\
\hline 40 & 250 & 8 & 0.756 & 0.772 & 51.8 \\
\hline 60 & 250 & 8 & 0.750 & 0.766 & 53.3 \\
\hline
\end{tabular}

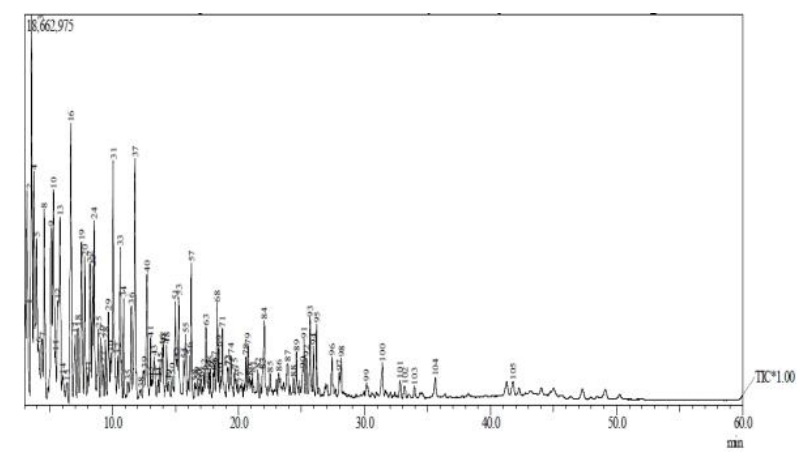

Figure 5. GCMS Analysis of Sample
After all program set up PS-6 fuel analyzed by GCMS. From GCMS analysis, following types of hydrocarbon compounds are appeared. Many compounds are emerged on the analysis carbon range $\mathrm{C}_{5}$ to $\mathrm{C}_{25}$. A liquid fraction consisting of paraffin, olefin, naphthene and aromatics (PONA). GCMS analysis for sample $\left(\mathrm{T}=250^{\circ} \mathrm{C}\right.$, catalyst $6 \%, \mathrm{t}=60$ minute $)$ can be seen in figure $\mathbf{5}$.

GCMS analysis of sample upon retention time following compounds are found initially such as at retention time 3.086, compound is $\mathrm{C}_{5} \mathrm{H}_{10}$, at retention time 3.199 , compound is $\mathrm{C}_{3} \mathrm{H}_{6} \mathrm{O}$, at retention time 3.545, compound is $\mathrm{C}_{6} \mathrm{H}_{14}$, at retention time 3.749, compound is $\mathrm{C}_{6} \mathrm{H}_{14}$, at retention time 3.954, compound is $\mathrm{C}_{6} \mathrm{H}_{14}$.

According to GCMS analysis, it is noted that composition of liquid fuel can be classified as paraffin, olefin, naphthene, aromatic and other compound which does not include the composition of petroleum, and its present was not expected, because it can decrease the quality of petroleum. Classification of liquid fuel composition can be seen in table 4 . 
Table 4. Classification of liquid fuel composition sampel (60-minute, $6 \%$ catalyst, $\left.250^{\circ} \mathrm{C}\right)$

\begin{tabular}{|l|c}
\hline Liquid fuel composition & $\%$ \\
\hline Paraffin & 59.17 \\
\hline Olefin & 14.8 \\
\hline Naphthene & 3.93 \\
\hline Aromatic & 21.93 \\
\hline Others & 0.17 \\
\hline
\end{tabular}

Table 4 shows that paraffin is the most abundant product with percentage $59.17 \%$. Subsequent abundant products are aromatic (21.93\%), napthene $(3.93 \%)$, Olefin $(14.8 \%)$ and another compound $(0.17 \%)$.

\section{CONCLUSION}

This experiment used bentonite catalyst that intended to find the optimum condition. There are some factors to be considered such as the use of the catalyst, length of cracking time and the optimum operating condition.

From the data showed the variation of catalyst weight influenced the percentage yield of product. In summary we can get the best product yield is influenced by the catalyst concentration of $6 \%$ with a cracking time of 60 minutes and from the GCMS analysis, the product yield shows the characteristics of gasoline.

\section{AUTHORS' CONTRIBUTIONS}

All authors contributed equally to this work.

\section{ACKNOWLEDGMENTS}

We gratefully thank the PNBP programme and Director of Politeknik Negeri Sriwijaya for financial support.

\section{REFERENCES}

[1] Onwudili JA, Insura N, Williams PT. Composition of products from the pyrolysis of polyethylene and polystyrene in a closed batch reactor: effects of temperature and residence time. J Anal Appl Pyrolysis. 2009;86:293-303.

[2] Demirbas, A., Al-Sasi, B.O. and Nizami, A.S., 2015. Conversion of waste tires to liquid products via sodium carbonate catalytic pyrolysis. Energy
Source Part A 38, 2487-2493.

[3] Farshi, R., Belthura, C., Athreyasa, R and Jeevan, J. Ramesh. 2013. Catalytic Degradation of Municipal Waste Plastics to Produce Fuel Range Hydrocarbons using Bentonite. Department

of Chemical Engineering, DSCE, Bangalore-560078. International Journal of Current Engineering and Technology. ISSN 2277-4106.

[4] Rehan, M., Nizami, A.S., Shahzad, K., Ouda, O.K.M., Ismail, I.M.I., Almeelbi, T., Iqbal, T., and Demirbas, A., 2016. Pyrolytic liquid fuel: a source of renewable electricity generation in Makkah. Energy Sources Part A. 38, 2598-2603

[5] Wu, J., Chen, T., Luo, X., Han, D., Wang, Z., dan $\mathrm{Wu}$, J., 2014. TG/FTIR analysis on co-pyrolysis behavior of PE, PVC and PS. Waste Manage. 34, 676-682.

[6] Syamsiro M, Saptoadi H, Norsujianto T, Noviasri Cheng S, Alimuddin Z, and Yoshikawa K. 2014. Fuel oil production from municipal plastic wastes in sequental pyrolysis and catalytic reforming reactors. Energy Procedia 47:180-188

[7] Kepdirjen Migas (2018). Standards and Quality of Fuel Type Gasoline RON 98 (Pertamax Turbo) Marketed in the Country. Decree of the Director General of Oil and Gas No: 0177.K / 10 / DJM.S / 2018 downloaded on August 28, 2020.

[8] Kumar S., Panda, A.K., and Singh, R.K., 2011, A Review on Tertiary Recycling of High-Density Polyethylene to Fuel, Resources, Conservation and Recycling Vol. 55 893-910.

[9] Kirk-Othmer Encyclopedia of Chemical Technology, vol. 12, fourth ed, John Wiley \& Sons, 2010, pp. 110-125.

[10] Sarker, Moinuddin, Mohammad Mamunor Rashid, Mohammad Molla, Md. Sadikur Rahman. 2011. Waste Polystyrene (PS-6). Plastic Conversion into liquid hydrocarbon fuel by using HZSM-5 catalyst with thermal degradation process. International Review of chemical engineering (I.RE. CH.E), Vol. 3 N.5.

[11] J. Aguado, D.P. Serrano, G.S. Miguel, J.M. Escola, J.M. Rodriguez, 2007, Catalytic activity of zeolitic and mesostructured catalysts in the cracking of pure and waste polyolefins. Journal of Analytical and Applied Pyrolysis, 78 (1) (2007), pp. 153-161.

[12] Hazrat, M.A., M.G. Rasul, M.M.K.Khan, 2015. A study on thermocatalytic degradation for production of clean transport fuel and reducing plastic waste. Procedia Engineering 105 (2015) 865-876 